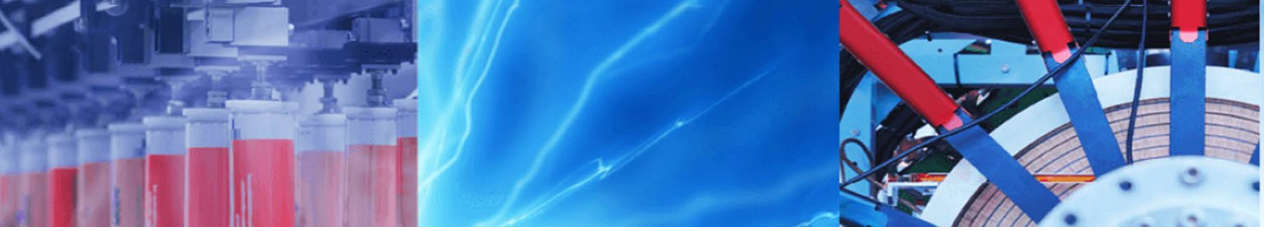

Research Article

\title{
Study of solutions to optimize the extraction of hemp fibers for composite materials
}

\author{
Marie Gregoire ${ }^{1}\left(\right.$ Emmanuel De Luycker $^{1} \cdot{\text { Mahadev } \text { Bar }^{1} \cdot \text { Salvatore Musio }}^{2} \cdot$ Stefano Amaducci $^{2} \cdot$ Pierre Ouagne $^{1}$
}

(c) Springer Nature Switzerland AG 2019

\begin{abstract}
Fibres from hemp stems can be extracted through different mechanical processes following dew or water retting etc. Extraction processes generally have a significant impact on mechanical and morphological properties of the fibres. In this study, hemp fibres are extracted following three different ways. In the first route hemp fibres are extracted from FUTURA 75 variety stems by performing scutching, hackling and microwave degumming. A second batch of fibres of the same variety was extracted by scutching and hackling after an initial microwave degumming treatment. In the third route, the same variety of hemp fibres are extracted from dew retted stems grown at Piacenza (Italy). Finally, the mechanical properties of single fibres as well as the fineness of technical fibres of all types of extracted fibres are evaluated and compared and the interest of the microwave degumming for hemp stem is evaluated.
\end{abstract}

Keywords Hemp · Microwaves degumming · Fineness · Mechanical properties

\section{Introduction}

Used for centuries in the textile industry and for sailing equipment such as sails or ropes, hemp declined in use and cultivation during the nineteenth and twentieth centuries [1]. Recently, there has been a significant rise in the number of hectares of hemp grown due to an increasing demand for seeds for a diversified use in the food sector [2]. Valorising both the seeds and the straws (particularly the fibres) would provide a non-negligible supplementary income to the farmers as proposed by [3]. Currently hemp fibres are mainly used for papermaking or as short fibre reinforcements for composites but there are no textile reinforcements dedicated to the reinforcement of load bearing composites from hemp.

For load bearing composite applications, it is necessary to preserve as much as possible the mechanical and morphological properties of the hemp fibres. Apart from the type of fibre extraction process that should exclude very aggressive devices such as hammer mills $[4,5]$, the second parameter that can have an influence is retting [6-9]. Retting is a process during which micro-organisms attack the pectic cements binding the fibres together and thus promote the refinement of the bundles [10]. The quality of the retting achieved will have an influence on the quality of the fibres because they will be much easier to extract and separate into fine and long technical fibres [11].

Water retting has long been used by immersing the stems in "open" water tanks [12]. This treatment greatly favours the fibre extraction, but it is prohibited in western Europe because of its high environmental impact $[13,14]$. This study will therefore focus on two different types of retting: dew retting and microwave retting (also called microwave degumming). The properties of fibres extracted after dew retting and after the use of microwave degumming are compared and analysed. The mechanical properties of the fibres are determined by carrying out tensile tests on single fibres. For this purpose, a tension device developed by Dia-Stron Ltd. is used. The morphological property

Marie Gregoire, marie.gregoire@enit.fr | 'Laboratoire Génie de Production, LGP, Université de Toulouse, INP-ENIT, Tarbes, France. ${ }^{2}$ Department of Sustainable Crop Production, Università Cattolica del Sacro Cuore, Piacenza, Italy. 
evaluation mainly consists in measuring their fineness by using a scanner type device.

\section{Materials and methods}

\subsection{Plant material}

The tests are carried out on hemp stems and fibres of the FUTURA 75 variety grown and harvested in Italy (Università Cattolica del Sacro Cuore, Piacenza). Different hemp varieties are developed by breeders using plant selection. FUTURA 75 is the brand name of a variety developed by the "Hemp-it" company (https://www.hemp-it.coop/) for dual purpose valorisation (both seeds and straw) so that to promote a higher income to farmers.

The hemp stems were harvested at the end of flowering, i.e. at the beginning of August, and cut into 2 sections of $1 \mathrm{~m}$ each. Some stems have been directly harvested and stored. It corresponds to the non-retted batch. Other stems were then retted in the field for 4 weeks before being packed in the form of bundles of oriented stems. This is the batch retted in the field. The two batches were coming from the same field.

Tests are performed on 2 types of samples. First of all, sections of unretted stems of 5 centimetres in length are taken from the central part of the stems since this area is expected to provide the best quality fibres [15] in flax and hemp. These samples are then immersed for $24 \mathrm{~h}$ in a water tank at room temperature to create polar molecules within the material and to allow the microwave treatment that is then carried out to be effective.

A second batch of samples is constituted from hemp fibres extracted by scutching from stems that have undergone the same types of harvesting and retting as in the previous batch. These fibres are then immersed in water at room temperature for $24 \mathrm{~h}$ before being degummed using microwave energy.

The last batch studied consists of hemp fibres obtained from stems dew-retted in the field and extracted by scutching and hackling using the same device and test parameters as for the previous batch.

\subsection{The fibre extraction device}

The extraction of fibres from hemp stems that have been retted in the field is carried out by scutching hackling using a device developed by Taproot Fibre Lab (Nova Scotia, Canada) as shown in Fig. 1.

The scutching hackling fibre extraction device is composed of 3 distinct modules. The first module consists of three successive pairs of fluted rollers designed to break the woody part of the stems. The material obtained at

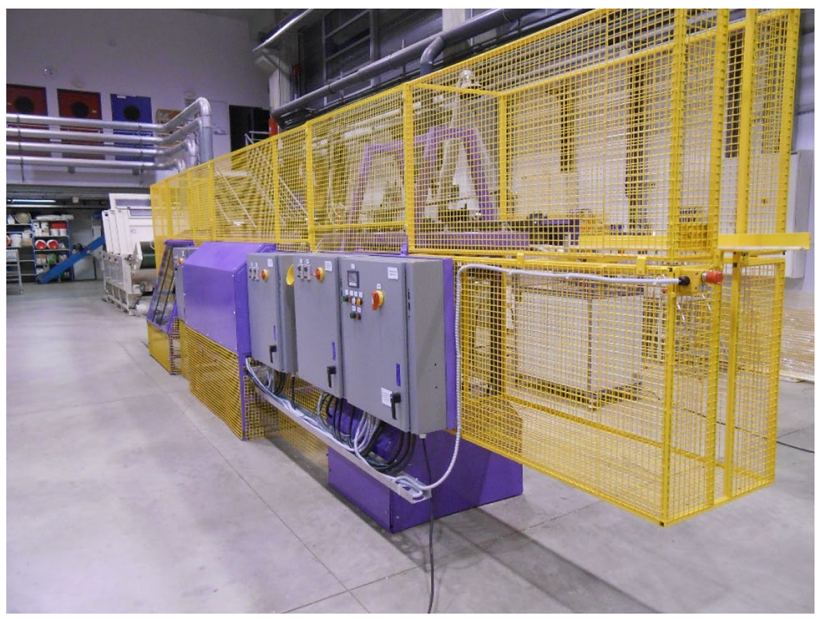

Fig. 1 Taproot fibre extraction device

the end of the breaking process is then transmitted to a scutching module. This scutching step removes the shives and plant dust trapped in the fibres. Finally, the material is passed through a hackling device to align and start separating the fibre bundles.

The long fibre bundles obtained at the outlet of the device may not be very well separated. In that case the need for additional degumming treatment before (on hemp stems) or after (on extracted fibres) extraction by scutching hackling may be used.

When microwave energy degumming tests are performed on the fibres, an additional hackling step is performed following the treatment on the hackling device.

\subsection{Microwave degumming}

Microwave degumming is used to obtain a better separation of the bundles and therefore subsequently obtain quality fibres suitable for composite materials for structural and semi-structural parts. This treatment attacks the middle lamella holding the fibres together. According to Nair et al. [16] or Cheng et al. [17], microwaves degrades the polar molecules created in the material during the soaking of the samples mentioned above. Pectin being a more polar molecule than cellulose, it is primarily degraded by the degumming treatment with microwave energy.

The tests were conducted on a microwave oven of adjustable power and processing time. The processing power used is the same as that chosen by Nair in its study, i.e. $2 \mathrm{~W}$ per gram of material [16].

The selected test parameters are presented in Table 1.

After degumming, the samples are rinsed 5 times with water at room temperature and then dried in an oven at $60{ }^{\circ} \mathrm{C}$ until they reach a humidity level of $8 \%$. 
Table 1 Microwave

degumming parameters

\begin{tabular}{ll}
\hline Microwave power & $2 \mathrm{~W} / \mathrm{g}$ \\
Exposure time & $20 \mathrm{~min}$
\end{tabular}

\subsection{Morphological analysis}

Forty bundles of fibres are randomly sampled from the material obtained at the end of the treatment. The average diameters of these bundles are then measured by image processing on the ImageJ software after taking images under an optical microscope (Olympus PMG3-F3, France). Three diameter measurements are made over the length of each bundle.

\subsection{Single fibre tensile tests}

Thirty elementary fibres are extracted manually from each batch in order not to damage them and to obtain properties as close as possible to their reinforcing potential. Each end of the individual fibre is positioned in plastic tabs and held in position with a UV-sensitive glue to prevent it from slipping during the tests.

The measurement of the cross-sections of the elementary fibres is carried out by using the "automated laser scanning" method which uses a shadow projection technique. A fibre dimensional analysis system (FDAS) controlled by Diastron Ltd.'s UV Win software, Hampshire, UK, shown in the Fig. 3 , is used to determine the diameters of individual fibres using a high-precision laser beam photodetector. The individual fibre mounted in the plastic shelves is positioned in jaws and held in position by a pneumatic system. The fibre is scanned on its $360^{\circ}$ periphery and along its entire length at regular intervals. For this study, fibres with a gauge length of $12 \mathrm{~mm}$ are scanned ten times in different ways over their entire length. During the rotation of the fibre, the maximum and minimum diameters are measured and correspond to real measurements. The other measurements correspond to projected diameters. The area of the fibre is then calculated from the maximum and minimum diameters by following an elliptical model. As explained by Garrat et al. [18], such a model is more provides results that are closer to the real area of the fibre, on the contrary to the circular model that is widely used. This measuring system allows diameters to be determined with an accuracy of $0.01 \mu \mathrm{m}$. However, it should be noted that this system does not allow the measurement of concave surfaces but this is very rare at the scale of individual fibres.

On the picture presented below [19], it is clearly visible that the percentage of fibres presenting high levels of concavity is globally not very high, but it exists. In our study, this amount was not measured.
Our study concentrates on the measurement of tensile properties of single fibres. As it is possible to see on Fig. 2, the fibres are not cylindrical, and their section may change along their length. This is why, a laser scanning system based on the "ombroscopy" principle was used so that to estimate with the highest accuracy the local cross section areas along the fibres. In most of the publications of the literature, the authors use optical microscopy measurements. In most of the cases, the fibres lay down on their larger diameter and this is the one that is taken into account to measure the cross section of the fibre using a cylindrical model. Over estimation of the diameter is generally performed and the tensile properties under-estimated.

Moreover, the fibres are not cylindrical and other models such as elliptical models should be used. This is why, the laser scanning device is used in this work so that to

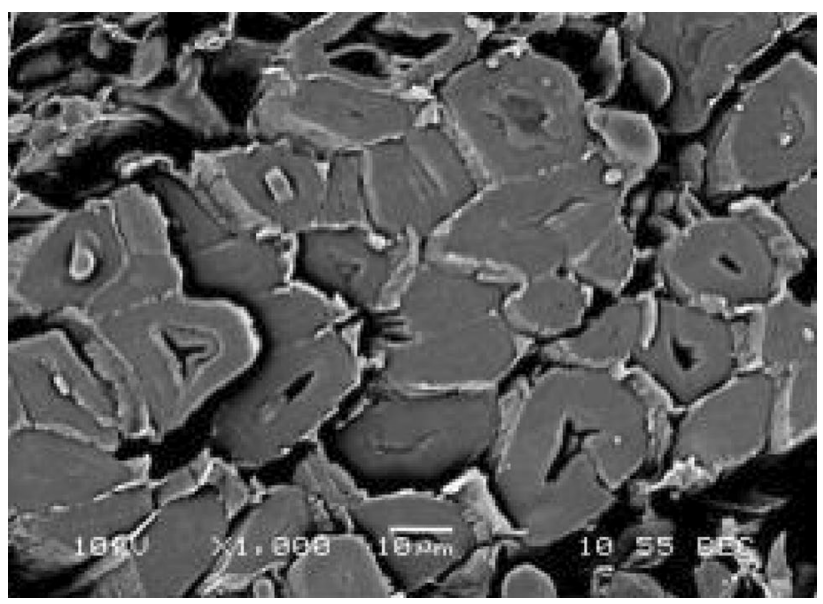

Fig. 2 Cross sectional sections of hemp fibres [19]

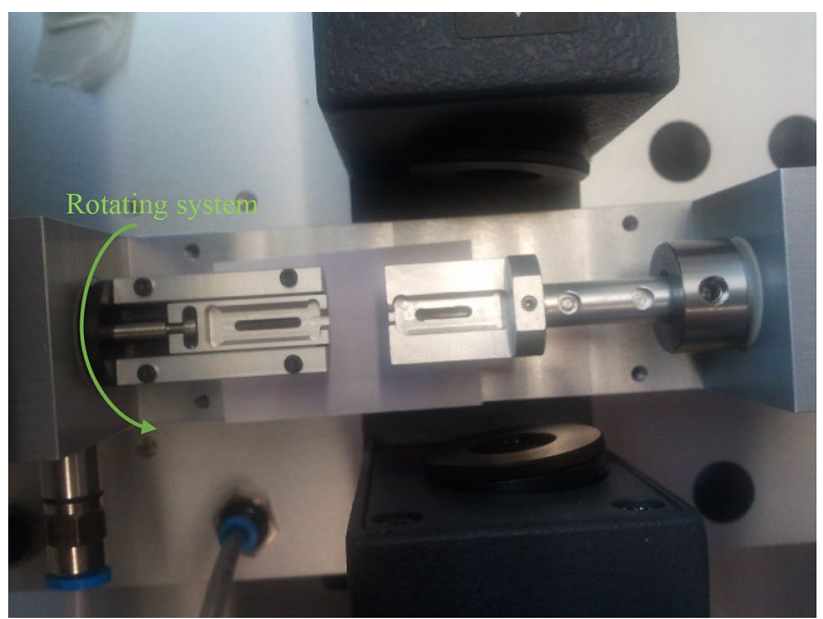

Fig. 3 Fibre dimensional analysis system 
decrease the cross section measurement errors even though small systematic errors can be encountered due to concavity. For technical fibres, Garat et al. [18] found that the cross section was under-estimated by $30 \%$ for flax and hemp technical fibres. In another study to be published, the authors found similar tendencies for hemp individual fibres. So the authors believe that the measurements performed in the frame of this work globally minimise the cross section measurements (Fig. 3).

Tensile tests are performed on specimens previously prepared for the diameter measurement of individual fibres. After calculating the cross-sectional areas of the individual fibres using an elliptical model, they are tested in tension. The system used is an automated high-precision extensometer (Lex 820, Dia-Stron Ltd., Hampshire, UK) composed of 2 elements: a load cell with a capacity of $\pm 20 \mathrm{~N}$ and a stepper motor for tension. It is used for low deformation ruptures. The displacement is obtained with an accuracy of $1 \mu \mathrm{m}$. The tests are performed with a displacement speed of $1 \mathrm{~mm} / \mathrm{min}$. The tensile strength and elastic muduli of the fibres can then be calculated.

\subsection{Statistical analysis}

Tests, called Student tests, are performed to determine if there is a statistical difference between two batches of samples in terms of mean values. A 95\% confidence interval is taken.

\section{Results}

\subsection{Morphological analysis}

Morphological analyses are carried out after each stage of microwave degumming on two types of materials: fibres obtained by scutching hackling and degumming or fibres obtained after degumming of un-retted stems followed by scutching/hackling. The results obtained are compared with fibres from hemp retted in the field and extracted by scutching hackling.

When the degumming is carried out directly on the hemp fibres, morphological analyses are carried out on the material before degumming, either at the end of scutching hackling, after the microwave energy treatment step and a final analysis is carried out after the additional hackling. When the degumming is carried out on the non-retted hemp stems, morphological analyses are carried out on the degummed material and then extracted by scutching hackling.

The results obtained are presented in Table 2 .
Table 2 Morphological analysis results; Batch 1: scutched and hackled un-retted; Batch 2: scutched, hackled and microwaved degummed; Batch 3: scutched, hackled, microwaved degummed and hackled again; Batch 4: microwave retted stems, scutched and hackled

Student tests were performed for each batch tested. The results obtained show first of all that there is no significant difference between non-retted and retted fibres after the scutching hackling extraction stage (Batch 1/ Batch 2). Dew retting in the field (as performed on the tested batches) therefore does not have a sufficient and significant impact on the degradation of the middle lamella and on the separation of the fibres. This result confirms that retting alone in the field (as performed in the frame of this study) may not be sufficient to obtain fibres of sufficient fineness for the manufacture of structural and semi-structural composite parts. Fibre diameters in the range $35-45 \mu \mathrm{m}$ are targeted. An additional processing such as microwave treatment could improve this fineness.

Microwave energy degumming performed after fibre extraction (Batch 2) significantly reduces the bundle diameters of un-retted fibres compared to dew-retted and un-retted fibres extracted by hackling scutching (Dew-retted and Batch 1/batch 2). This conclusion is also valid when the degumming is performed on the stems (Dew-retted and Batch 1/Batch 5). Thus, microwave degumming significantly improves the fineness of the material obtained. However, the additional hackling carried out following the degumming (Batch 2/Batch 3 ) does not have a significant impact on fibre separation.

The high dispersion of the results observed is classical. First, the tests are carried out on randomly selected bundles, which results in the presence of bundles of 2 or 3 fibres as well as large bundles of fibres in the batches tested. In addition, the samples with the greatest dispersion are the non-retted and dew-retted batches. In this case, the fibres are not very well separated from each other, which leads to the presence of very large bundles. Fine fibres can also be observed. When the degumming is carried out, the action of the microwaves concentrates mainly on the middle lamella binding the fibres together. This leads to a refinement of all the bundles with an even more marked impact on the very large bundles. In addition, the additional hackling carried out permits to increase the fibre separation and reduces the fibre distribution width. 
Table 3 Tension test results; dew-retted: dew retted scutched and hackled; Batch 1: scutched and hackled un-retted; Batch 2: scutched, hackled and microwaved degummed; Batch 3: scutched, hackled, microwaved degummed and hackled again; Batch 4: microwave retted stems, scutched and hackled

\begin{tabular}{lll}
\hline Batches & Failure stress (Mpa) & $\begin{array}{l}\text { Young } \\
\text { modulus } \\
\text { (Gpa) }\end{array}$ \\
\hline Dew retted & $822 \pm 400$ & $48 \pm 24$ \\
Batch 1 & $791 \pm 415$ & $51 \pm 20$ \\
Batch 2 & $969 \pm 431$ & $45 \pm 18$ \\
Batch 3 & $666 \pm 261$ & $33 \pm 16$ \\
Batch 4 & $857 \pm 267$ & $43 \pm 19$ \\
Marrot et al. [20] & 889 & 35 \\
\hline
\end{tabular}

\subsection{Mechanical analysis}

Mechanical analyses are carried out on the same batches as those studied for the morphological analyses. Thirty individual fibres were tested for each batch.

The results of the tensile tests are presented in Table 3.

Student tests were also performed for each batch tested to determine if they are significantly different.

No significant difference is observed between dew retted and microwave degumming performed on stem tensile properties (Dew retted and Batch 4). The microwave degumming does not degrade the high mechanical potential of the fibres. Student tests were carried out on the different batches with Batch 1 (scutched and hackled without any kind of retting or degumming) as a reference. The results show that the microwave treatment has no significant impact on the tensile properties of the fibres (Batch 1/ Batch 2). However, the additional hackling of the fibres has a negative impact on their potential (Batch 2/Batch 3). If the treatment is carried out on the stems before scutching and hackling, it is possible to obtain better properties than if scutching is carried out without pre-treatment (Batch 1/ Batch 5). The properties obtained after microwave degumming are comparable to those of elementary hemp fibres extracted manually and are even high if one considers the elastic modulus [20]. This therefore means that the microwave degumming does not degrade the tensile properties of the hemp fibres.

\section{Conclusions}

The manufacture of load bearing composite requires the use of well separated technical fibres. If this can be well obtained for flax fibres following dew-retting procedures in production zones such as Normandy (France), similar procedures are not yet optimised for hemp. As an alternative, another type of retting using microwave energy was proposed with success. This type of retting permits to significantly reduce the technical fibre diameter to suitable targeted values in the range $35-45 \mu \mathrm{m}$ and does not reduce the high potential of the individual fibres. The potential of this technique was therefore demonstrated and further studies should be performed to investigate the environmental and economical cost of such a technique at the industrial level.

Acknowledgements This project has received funding from the BioBased Industries Joint Undertaking under the European Union's Horizon 2020 research and innovation program under Grant Agreement No 744349 - SSUCHY project.

\section{Compliance with ethical standards}

Conflict of interest On behalf of all authors, the corresponding author states that there is no conflict of interest.

\section{References}

1. Bouloc P (2013) Hemp: industrial production and uses. CABI, Wallingford

2. Karus M, Karst S, Hobson J, Bertucelli S (2013) The European Hemp Industry: cultivation, processing and applications for fibres, shivs and seeds. Eur Ind Hemp Assoc 1994(2016-05):1-9. https://doi.org/10.1016/j.jallcom.2015.04.081

3. Tang K, Struik PC, Yin X, Thouminot C, Bjelková M, Stramkale V, Amaducci S (2016) Comparing hemp (Cannabis sativa L.) cultivars for dual-purpose production under contrasting environments. Ind Crops Prod 87:33-44

4. Xu J, Chen Y, Laguë C, Landry H, Peng Q (2012) Analysis of energy requirement for hemp fibre decortication using a hammer mill. Can Biosyst Eng. https://doi.org/10.7451/CBE.2012.54.2.1

5. Baker ML, Chen Y, Laguë C, Landry H, Peng Q, Zhong W (2013) Fiber yield and energy requirement of hemp decortication using a hammermill. Appl Eng Agric 29(4):453-460. https://doi. org/10.13031/aea.29.8463

6. Musio S, Müssig J, Amaducci S (2018) Optimizing hemp fiber production for high performance composite applications. Front Plant Sci 9:1-14. https://doi.org/10.3389/fpls.2018.01702

7. Liu M, Silva AS, Fernando D, Meyer A, Bo Madsen B, Daniel G, Thygesen A (2016) Controlled retting of hemp fibres: Effect of hydrothermal pre-treatment and enzymatic retting on the mechanical properties of unidirectional hemp/epoxy composites. Compos Part A 88:253-262

8. Liu M, Fernando D, Daniel G, Madsen B, Meyer AS, Ale MT et al (2015) Effect of harvest time and field retting duration on the chemical composition, morphology and mechanical properties of hemp fibers. Ind Crops Prod 69:29-39

9. Mazian B, Bergeret A, Benezet J-C, Malhautier L (2018) Influence of field retting duration on the biochemical, microstructural, thermal and mechanical properties of hemp fibres harvested at the beginning of flowering. Ind Crops Prod 116:170-181. https ://doi.org/10.1016/j.indcrop.2018.02.062

10. Liu M, Ale MT, Klaczkowski B, Fernando D, Daniel G, Meyer A, Thygesen A (2017) Comparison of traditional field retting and Phlebia radiata Cel 26 retting of hemp fibres for fibre-reinforced composites. AMB Express 7, Article number: 58 
11. Müssig J, Martens R (2008) Quality aspects in hemp fibre production-influence of cultivation. Harvest Retting Qual Asp Hemp Fibre Prod 7881:10-32. https://doi.org/10.1300/J237v 08n01

12. Clarke RC (2010) Traditional fiber hemp (Cannabis) production, processing, yarn making, and weaving strategies-functional constraints and regional responses. Part 2. J Nat Fibers 7(3):229250. https://doi.org/10.1080/15440478.2010.504043

13. Paridah T, Amel A, Syeed S, Zakiah A (2011) Retting process of some bast plant fibres and its effect on fibre quality: a review. BioResources 6:5260-5281

14. Horne MRL (2012) Bast fibres: hemp cultivation and production. Handbook of natural fibres, vol 1. Woodhead Publishing Limited, Sawston. https://doi.org/10.1016/B978-1-84569-697-9.50006-0

15. Charlet K, Baley C, Morvan C, Jernot JP, Gomina M, Breard J (2007) Characteristics of Hermès flax fibres as a function of their location in the stem and properties of the derived unidirectional composites. Compos A Appl Sci Manuf 38(8):1912-1921

16. Nair GR, Lyew D, Yaylayan V, Raghavan V (2015) Application of microwave energy in degumming of hemp stems for the processing of fibres. Biosys Eng. https://doi.org/10.1016/j.biosy stemseng.2014.12.012

17. Cheng C, Guo R, Lan J, Jiang S (2017) Extraction of lotus fibres from lotus stems under microwave irradiation. R Soc Open Sci 4:170747. https://doi.org/10.1098/rsos.170747
18. Garat W, Corn S, Le Moigne N, Beaugrand J, Bergeret A (2018) Analysis of the morphometric variations in natural fibres by automated laser scanning: towards an efficient and reliable assessment of the cross-sectional area. Compos Part A Appl Sci Manuf 108:114-123. https://doi.org/10.1016/j.composites a.2018.02.018

19. Bourmaud A, Beaugrand J, Shah DU, Placet V, Baley C (2018) Towards the design of high-performance plant fibre composites. Prog Mater Sci 97:347-408. https://doi.org/10.1016/j.pmats ci.2018.05.005

20. Marrot L, Lefeuvre A, Pontoire B, Bourmaud A, Baley C (2013) Analysis of the hemp fiber mechanical properties and their scattering (Fedora 17). Ind Crops Prod 51:317-327. https://doi. org/10.1016/j.indcrop.2013.09.026

Publisher's Note Springer Nature remains neutral with regard to jurisdictional claims in published maps and institutional affiliations. 